\title{
Long-term loss assessment of coastal bridges from hurricanes incorporating overturning failure mode
}

\author{
Deming Zhu ${ }^{1,2}$, Yaohan Li ${ }^{2}$, You Dong ${ }^{2^{*}}$ (D) and Peng Yuan ${ }^{2}$
}

* Correspondence: you.dong@polyu.
edu.hk
²Department of Civil and
Environmental Engineering, The
Hong Kong Polytechnic University,
Hung Hom, Kowloon, Hong Kong
Full list of author information is
available at the end of the article

\section{Springer Open}

\begin{abstract}
Coastal highway bridge is an essential component of the transportation system but threatened by natural hazards such as hurricanes. Damaged highway bridges result in not only transportation disruption, but also tremendous financial, societal, and life loss. Therefore, vulnerability and loss assessments of bridges under hurricane events are becoming primary concerns for decision-makers. This study provides an elaborate framework to assess the vulnerability and long-term loss of coastal bridges subjected to hurricane hazards based on three-dimensional (3D) numerical analyses. A 3D Computational Fluid Dynamics (CFD) numerical model is established to investigate wave-bridge interaction and a Finite Element (FE) model is established for the bridge to calculate structural responses under wave impacts. Based on the numerical results, the effects of wave force and overturning moment on structural capacity are studied and a probabilistic vulnerability model is developed. Structural demand, capacity, and limit states are determined, respectively. Uncertainties associated with wave parameters, structural capacity, and material properties, and the resulting consequences are considered. Then, fragility curves are calculated, and long-term damage loss is assessed. The proposed approach can benefit the management and design of coastal bridges against the impacts of hurricane hazards.
\end{abstract}

Keywords: Highway bridges, 3D numerical models, Long-term loss, Overturning effects, Structural response, Vulnerability model

\section{Introduction}

Coastal highway bridge, as a crucial component of the transportation system, is exposed to increasing failure risk from worldwide natural disasters such as hurricanes in recent years. Much damage is attributed to the storm surge and wave loads on bridge superstructures, which has motivated researchers to investigate wave-bridge interaction mechanisms in the last decade (Padgett et al. 2008; Xu and Cai 2015b). The investigations of wave load on coastal bridges through laboratory experiments and analytical methods (Guo et al. 2015; Hayatdavoodi et al. 2014; Seiffert et al. 2014; Xu et al. 2016) have laid the foundation as a preliminary guideline, and the first guide specification for bridge vulnerable to coastal storms was published in 2008 (AASHTO 2008). More

(c) The Author(s). 2021 Open Access This article is licensed under a Creative Commons Attribution 4.0 International License, which permits use, sharing, adaptation, distribution and reproduction in any medium or format, as long as you give appropriate credit to the original author(s) and the source, provide a link to the Creative Commons licence, and indicate if changes were made. The images or other third party material in this article are included in the article's Creative Commons licence, unless indicated otherwise in a credit line to the material. If material is not included in the article's Creative Commons licence and your intended use is not permitted by statutory regulation or exceeds the permitted use, you will need to obtain permission directly from the copyright holder. To view a copy of this licence, visit http://creativecommons.org/licenses/by/4.0/. 
specific and detailed analyses are required for real bridge systems considering the complex hydrodynamic problem (AASHTO 2008). In addition, studies associated with the development of reliable bridge systems mainly focused on the characterization and reduction of the vulnerability of the systems and the impacts of disaster events on system users (Dong et al. 2020; Li et al. 2020b). However, loss analysis may calculate a biased result due to the lack of in-depth understanding of structural responses. To address these issues, this study aims to perform vulnerability and long-term loss assessment of a coastal bridge subjected to hurricane disasters based on a detailed structural analysis.

There have been growing concerns about the wave impacts on coastal bridges since the severe Hurricanes Katrina (2005) and Ivan (2004). One of the failure modes leading to the severe damage is deck unseating caused by vertical wave load exceeding deck weight (Padgett et al. 2008). In addition, the bridge deck can be displaced by the horizontal wave force as long as it is large enough (Chen et al. 2016b). However, the wave induced overturning moment and bearing constraints have not been well investigated. For instance, AASHTO (2008) recommended selecting the moment center at the bottom of landward girder, while Cai et al. (2018) suggested it at the center of the bent beam to account for the pressure on the bridge substructure. Xu (2020) pointed out such method may underestimate the effects of horizontal force. Ataei and Padgett (2015) established a Fluid Structure Interaction model to compute the structural response using ADINA software package, but the effects of bearing constraints were not considered. Xu and Cai (2015a) utilized a simplified spring and damper system to simulate the connection between bridge superstructure and substructure, which could not fully address bearing constraints for practical engineering design. All these studies pointed out the necessity of a systematic structural response analysis of coastal bridge under wave impacts. Recognizing this, this study establishes a three-dimensional (3D) Computational Fluid Dynamics (CFD) model to compute the wave induced force and moment on the bridge deck. The results are then imported into a spatial bridge Finite Element (FE) model to calculate detailed structural responses with considering bearing constraints.

Currently, only a few studies have been conducted on the reliability assessment of coastal bridges under hurricanes (Ataei and Padgett 2013; Li et al. 2020b; Mondoro et al. 2017), and to the best knowledge of the authors, none of them accounted for overturning effects and bearing constraints. Ataei and Padgett (2013) first proposed the probabilistic vulnerability model on the deck unseating failure mode of coastal bridge caused by wave force. Saeidpour et al. (2019) discussed uncertainties associated with structural demand and capacity and pointed out the lack of detailed bridge failure model. Kameshwar and Padgett (2014) also pointed out the necessity of a more thorough failure model considering wave overturning effects. Therefore, given various sources of uncertainties pertaining to structural system and load characteristics, as well as the numerical results computed from the established CFD and FE models, a probabilistic vulnerability model of coastal bridge subjected to hurricane wave impacts is established targeting on both wave force and overturning moment.

The hurricane-induced consequences on coastal bridges are commonly measured in terms of financial losses, which is vital to aid the decision-maker to mitigate potential losses and enhance preparedness (Dong and Frangopol 2017; Frangopol et al. 2017). Previous loss assessment for hurricane hazard mainly focused on the unseating failure 
mode, and few studies incorporated component-level analysis. For example, Kameshwar and Padgett (2014) performed the risk assessment of highway bridges subjected to hurricane hazard, but only the deck unseating failure mode was considered. Neglecting the effects of overturning moment and bearing constraints may result in the inappropriate estimation of hurricane induced loss, and a more thorough model is required to address this issue. Thus, long-term loss assessment incorporating the overturning failure mechanism and effects of bearing constraints is performed in this study. The results are compared with previous methods for illustrative purpose.

Overall, this study aims to perform probabilistic vulnerability and long-term loss analyses of coastal bridges subjected to hurricane hazards based on an insightful exploration of the wave-deck interaction. 3D CFD model and FE models for the investigated bridge are established to explore wave influences and structural responses. Based on the numerical results, a probabilistic failure model of bridge under wave impacts is established, in which the effects of wave induced force and overturning moment are evaluated. Subsequently, longterm damage loss assessment during the bridge service life is calculated based on the homogeneous Poisson process. These results could aid the management, maintenance, and optimal structural design of coastal bridges. The remainder of the paper is organized as follows. CFD modeling and computational results are introduced in section 2. Bearing constraints, FE modeling, and calculation of structural responses are presented in section 3. A probabilistic vulnerability model incorporating the overturning failure mechanism is developed in section 4. Long-term loss analyses are discussed in section 5. Conclusions and future work are shown in section 6.

\section{Wave force and overturning moment on bridge deck computed by 3D CFD model}

\subsection{D CFD domain and model setups}

The investigated bridge model is a typical simply supported bridge as shown in Fig. 1. This type of bridge is widely built in coastal region and the old bridge design could not fully meet the requirement under climate change scenarios (Robertson et al. 2007). The combined effects of increasing sea level rise and amplification of hurricane intensity are threatening structural safety (Douglass et al. 2004). As shown in Fig. 1, the investigated bridge model is $15.85 \mathrm{~m}$ long and $9.6 \mathrm{~m}$ wide. The deck thickness is $0.18 \mathrm{~m}$, and $6 \mathrm{I}$ shaped girders, with a height of $1.37 \mathrm{~m}$, are evenly distributed along the deck. The initial water depth before surge and wave arrive is set as $12.5 \mathrm{~m}$, and the clearance is $4 \mathrm{~m}$.

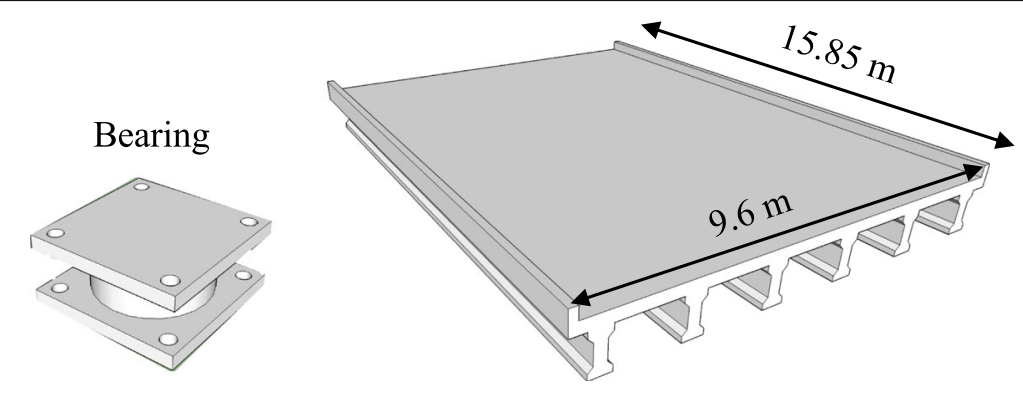

Fig. 1 Bridge model and bearing constraint 
The 3D CFD model of the investigated bridge is established with ANSYS Fluent package as shown in Fig. 2. The numerical domain is $140 \mathrm{~m}$ long in $x$ direction, $30 \mathrm{~m}$ high in $y$ direction, and $20.85 \mathrm{~m}$ wide in $z$ direction, i.e., there is $2.5 \mathrm{~m}$ reserved at both ends of the deck. The bridge model is located $20 \mathrm{~m}$ from the velocity inlet domain. Plane ABCD is set as velocity inlet plane to generate solitary waves by using User Defined Functions (UDF) (Chen et al. 2016a). Plane EFGH is set as pressure outlet plane and there is a 100-m long distance between the bridge model and plane EFGH to minimize wave reflection effects. Plane AEHD is a pressure outlet plane with one atmosphere (i.e., $101.325 \mathrm{kPa}$ ). The rest planes are set as stationary walls. The solitary wave particle velocities $u$ and $v$ when transmitting a wave are calculated as (Sarpkaya and Isaacson 1981)

$$
\begin{aligned}
& \frac{u}{\sqrt{g D}}=\varepsilon \operatorname{sech}^{2} q+\varepsilon^{2} \operatorname{sech}^{2} q\left\{\frac{1}{4}-\operatorname{sech}^{2} q-\frac{3}{4}\left(\frac{s}{D}\right)^{2}\left(2-3 \operatorname{sech}^{2} q\right)\right\} \\
& \frac{v}{\sqrt{g D}}=\varepsilon \sqrt{3 \varepsilon}\left(\frac{s}{D}\right) \operatorname{sech}^{2} q \tanh q\left\{1-\varepsilon\left[\frac{3}{8}+2 \operatorname{sech}^{2} q+\frac{1}{2}\left(\frac{s}{D}\right)^{2}\left(1-3 \operatorname{sech}^{2} q\right)\right]\right\} \\
& q=\frac{\sqrt{3 \varepsilon}}{2 D}\left(1-\frac{5}{8} \varepsilon\right)(x-c t)
\end{aligned}
$$

where $D=$ water depth; $H$ = wave height; $g$ = gravitational acceleration; $x$ = coordinate; $t=$ time; $\varepsilon=H / D ; s=y+D$; and $y=$ the distance from the still water level to the wave crest, which is negative if the free surface is lower than the initial water level.

In the CFD model, the Volume of Fluid method (VOF) is utilized to compute the free water surface with air set as phase-1 and water-liquid set as phase-2 (Chen et al. 2020). The SST $k-\omega$ model is adopted and the turbulence damping factor is taken as 50 . The turbulent intensity and viscosity ratio of the boundaries are set as $2 \%$ and $10 \%$, respectively. Tetrahedron mesh is utilized to fit the irregular bridge shape and mesh sizes are examined by performing sensitivity analysis to satisfy the Courant Number (Robertsson and Blanch 2020). After test and comparison for different setups, the tetrahedron mesh size is set as $0.6 \mathrm{~m}$ and the fixed time step is $0.01 \mathrm{~s}$, which could result in a suitable Courant Number ranging from $0 \sim 0.4$. The total mesh number of the numerical model is 3,505,118. Detailed information and experimental validation of the established model could be found in Zhu and Dong (2020). With the established 3D CFD model, wave induced force and overturning moment under various surge and wave conditions can be calculated.

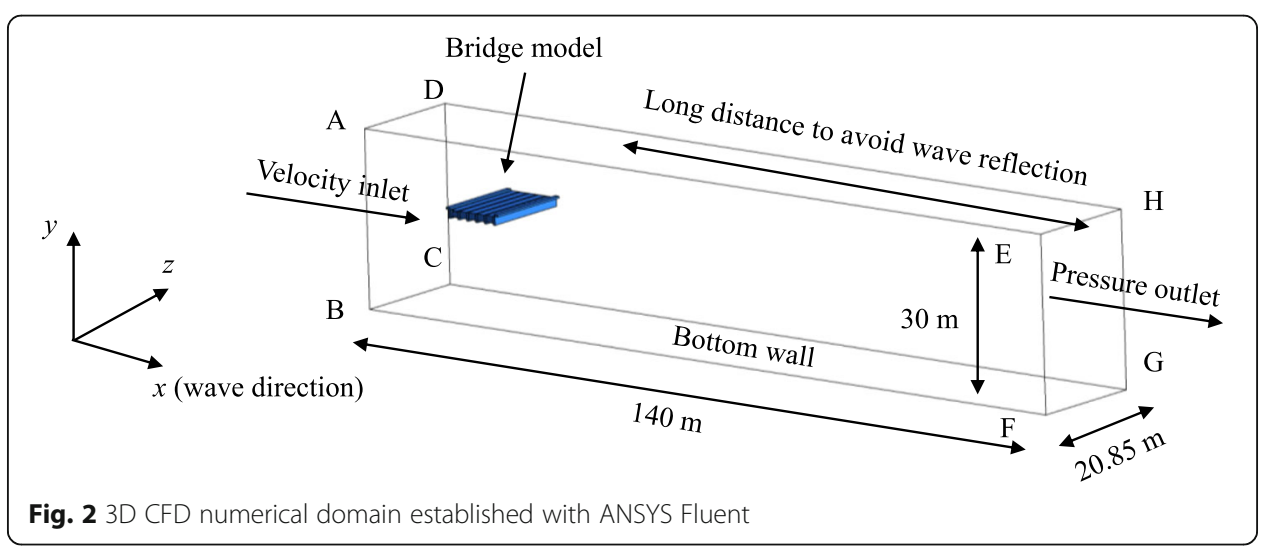




\subsection{Wave induced force and overturning moment}

Time histories of wave induced force $\left(F_{V}\right.$ and $\left.F_{H}\right)$ and moment $(M)$ of a typical case with $D=15 \mathrm{~m}, H=3.6 \mathrm{~m}$, and $Z_{c}=1.5 \mathrm{~m}$ are plotted in Fig. 3 . The reference point of the overturning moment is determined at the bottom of the landward girder, which corresponds to the numerical analysis of structural responses and in line with the guide specification (AASHTO 2008). The vertical and horizontal wave forces increase to the peak and then drop down as the wave flow passes the bridge, as shown in Fig. 3a. Similar trend of increasing first and then decreasing is observed for overturning moment $M$ as Fig. 3b. The peak of $F_{V}$ is much larger than $F_{H}$, and the maximum values of $F_{V}, F_{H}$, and $M$ occur almost simultaneously, at about $20.5 \mathrm{~s}$.

By tracing time histories of wave force and moment, several critical points which may affect structural stability are determined as: (1) maximum vertical force $F_{V \text {-MAX }}$ which could over the deck weight and lift the deck; (2) maximum horizontal force $F_{H \text {-MAX }}$ which may exceed lateral constraint from the bearings and the friction force between bridge superstructure and substructure; and (3) maximum moment $M_{\mathrm{MAX}}$ which may damage local constraint at the seaward side and overturn the deck. Typical results under different wave and inundation conditions calculated from the CFD model are presented in Fig. 4. As indicated in Fig. 4a, $F_{V \text {-MAX }}$ increases with the wave height $H$, but the increment rate changes with different water depth $D$. Under submerged conditions $\left(Z_{c}=-2.1 \mathrm{~m}\right)$, wave height $H$ has little influence on $F_{V \text {-MAX }}$. The maximum value of $F_{V \text {-MAX }}$ occurs when the initial water level is close to the deck position. The maximum horizontal force $F_{H \text {-MAX }}$ shows different characteristics from $F_{V-\mathrm{MAX}}$, which is less influenced by the water depth $D$ but more by the wave height $H$. $F_{H \text {-MAX }}$ has close values under different water depths for small wave heights $(H=3.6$ and $4.2 \mathrm{~m})$. The maximum moment $M_{\mathrm{MAX}}$ has a similar trend to $F_{V \text {-MAX }}$ and has the maximum value when $Z_{c}$ is the smallest, which means it is attributed to the vertical force component significantly. The extreme overturning moment leads to uneven loading distribution on the bridge deck, which may destroy local components (e.g., bearing) and overturn the deck. It is necessary to conduct structural response analyses of coastal bridges under wave impacts.

\section{Bridge structural responses under wave impact based on FE numerical analysis}

\subsection{FE modeling for the bridge and boundary conditions}

To investigate the structural performance and capacity of the coastal bridge under extreme wave impacts, a spatial FE bridge model is established to compute structural responses by
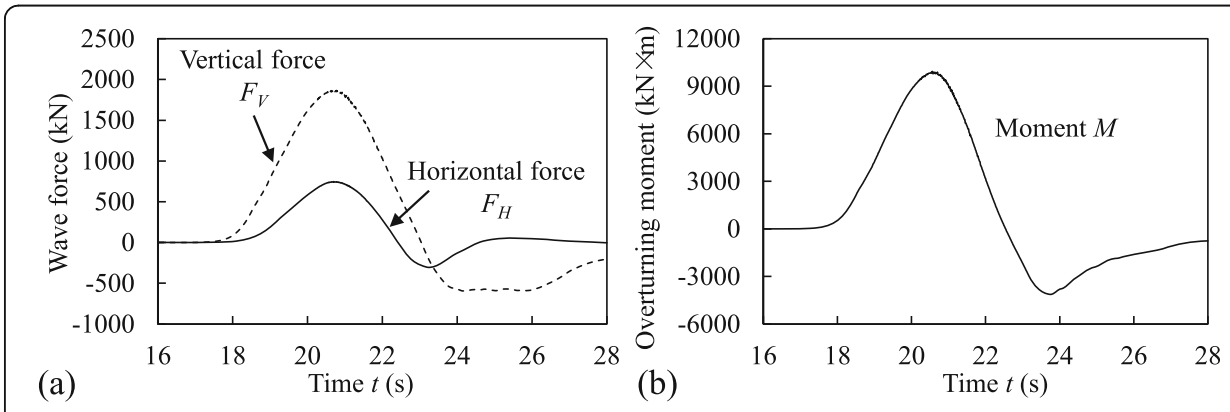

Fig. 3 Time histories of wave induced vertical force, horizontal force, and moment 


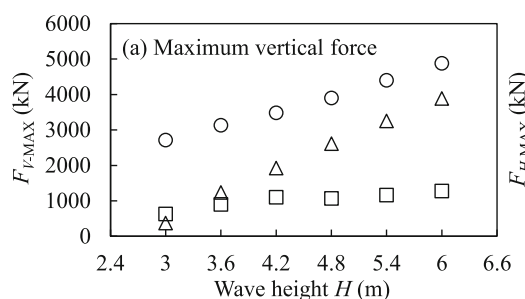

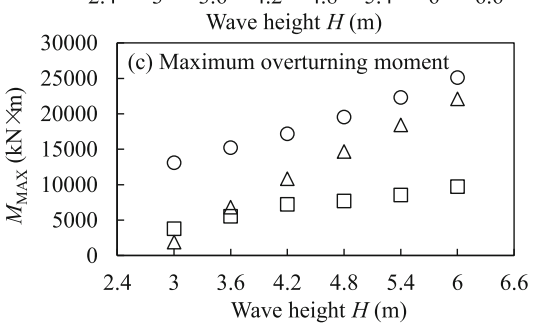

Fig. 4 Maximum wave force and overturning moment under different conditions (b) Maximum horizontal force

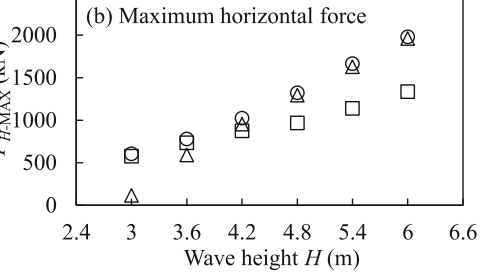

$\triangle D=14.4 \mathrm{~m}, Z_{c}=2.1 \mathrm{~m}$, unsubmerged

○ $D=16.2 \mathrm{~m}, Z_{c}=0.3 \mathrm{~m}$, unsubmerged

$\square D=18.6 \mathrm{~m}, Z_{c}=-2.1 \mathrm{~m}$, submerged

using ANSYS Mechanical APDL package. The established bridge model and bearing constraints are shown in Fig. 5, where the wave induced forces are applied on different girder and deck components. Constraints are set at bearings according to real bridge design as shown in Table 1 (Caltrans 1994; Khaleghi et al. 2019). All the bearings are set as compression only and the constraints in horizontal direction $(x)$ are set at bearings L3 and R3. To accurately calculate structural responses, the bridge deck is divided into 6 parts as Fig. 5 (b), and time histories of wave forces on each part (surface) are extracted from the CFD model and then input into the FE model. Surface load, which is evenly distributed along the longitudinal direction ( $z$ direction), is applied on the bridge span.

In the FE model, SOLID 65 and COMBIN 39 (compression only) are used to simulate the concrete and constrain of each bearing. The stiffness of COMBIN is set as $1 \times$ $10^{10} \mathrm{~N} / \mathrm{m}$. For SOLID 65, the modulus of elasticity $(\mathrm{EX})=3.524 \times 10^{4} \mathrm{~N} / \mathrm{mm}^{2}$; Poisson's ratio $=0.167$; density $=2600 \mathrm{~kg} / \mathrm{m}^{3}$; shear transfer coefficient for open crack $=0.3$; and shear transfer coefficient for closed crack $=0.5$. The ultimate concrete compressive strength $f_{c}^{\prime}$ is taken as $37.1 \mathrm{MPa}$ and the axial tensile cracking stress $f_{t}^{\prime}$ is $3.25 \mathrm{MPa}$ (ACI 2014). It is assumed that there is no descent stage for the concrete, and the stressstrain relationship is defined as (ACI 2014)

$$
\sigma_{c}=f_{c}^{\prime}\left[1-\left(1-\frac{\varepsilon_{c}}{\varepsilon_{0}}\right)^{2}\right] \varepsilon_{c} \leq \varepsilon_{0}
$$

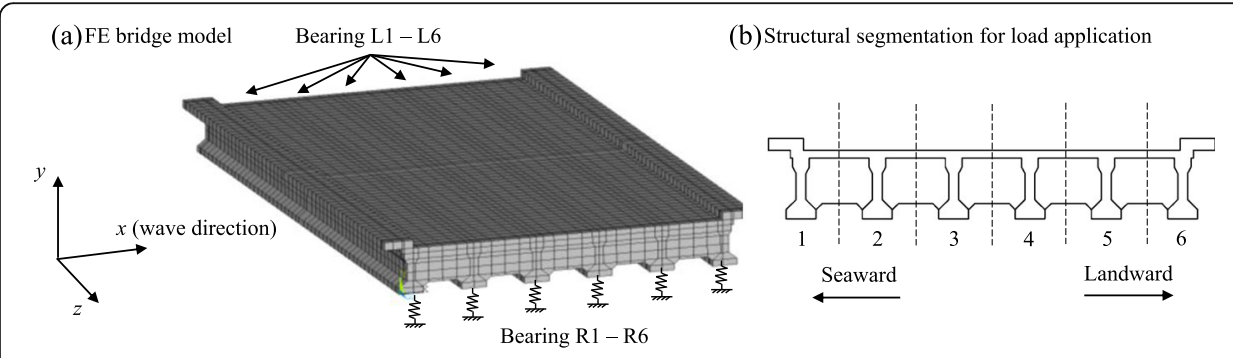

Fig. 5 a FE bridge model and bearing constraints and $\mathbf{b}$ structural segmentation for load application 
Table 1 Bearing constraints of the bridge model

\begin{tabular}{llllllll}
\hline No. & $\boldsymbol{x}$ & $\boldsymbol{y}$ & $\boldsymbol{z}$ & No. & $\boldsymbol{x}$ & $\boldsymbol{y}$ & $\boldsymbol{z}$ \\
\hline R1 & - & C_O & Constrained & L1 & - & C_O & - \\
R2 & - & C_O & Constrained & L2 & - & C_O & - \\
R3 & Constrained & C_O & Constrained & L3 & Constrained & C_O & - \\
R4 & - & C_O & Constrained & L4 & - & C_O & - \\
R5 & - & C_O & Constrained & L5 & - & C_O & - \\
R6 & - & C_O & Constrained & L6 & - & C_O & - \\
\hline
\end{tabular}

Note: C_O refers to compression only bearings

$$
\sigma_{c}=f_{c}^{\prime} \quad \varepsilon_{0} \leq \varepsilon_{c} \leq \varepsilon_{c u}
$$

where $\sigma_{c}=$ concrete stress; $\varepsilon_{c}=$ concrete strain; and $\varepsilon_{O}$ and $\varepsilon_{c u}=$ peak and ultimate strains, which equal 0.002 and 0.0033 , respectively.

\subsection{Bearing reactions under different loading conditions}

Given relevant parameters used in the bridge FE model, bearing reaction forces and working states can be calculated as shown in Fig. 6. In Fig. 6, a positive value represents the compressed (normal) working state, while a zero value refers to the disengaged (damage) state, because tension force (negative value) is not allowed for compressiononly bearings. Disengaged bearing no longer provides constraint. Since the lateral constraint ( $x$ direction) is set at the $\mathrm{R} 3$ bearing at the $\mathrm{R}$ end of the span as Table 1 , there is little difference between reaction forces of the left and right bearings. The deck weight is about $219.4 \times 10^{3} \mathrm{~kg}$ per span, and the overturning capacity from the deck weight is calculated as $9298 \mathrm{kN} \times \mathrm{m}$. Figure $6 \mathrm{a}$ shows the case where the maximum overturning moment $M_{\mathrm{MAX}}=3023 \mathrm{kN} \times \mathrm{m}$, which is relatively small as compared with the capacity from the deck weight. All the bearings are working properly. With the increase of maximum wave force and overturning moment as shown in Figs. $6 \mathrm{~b}-\mathrm{d}$, more bearings are damaged, which significantly reduces structural stability and the
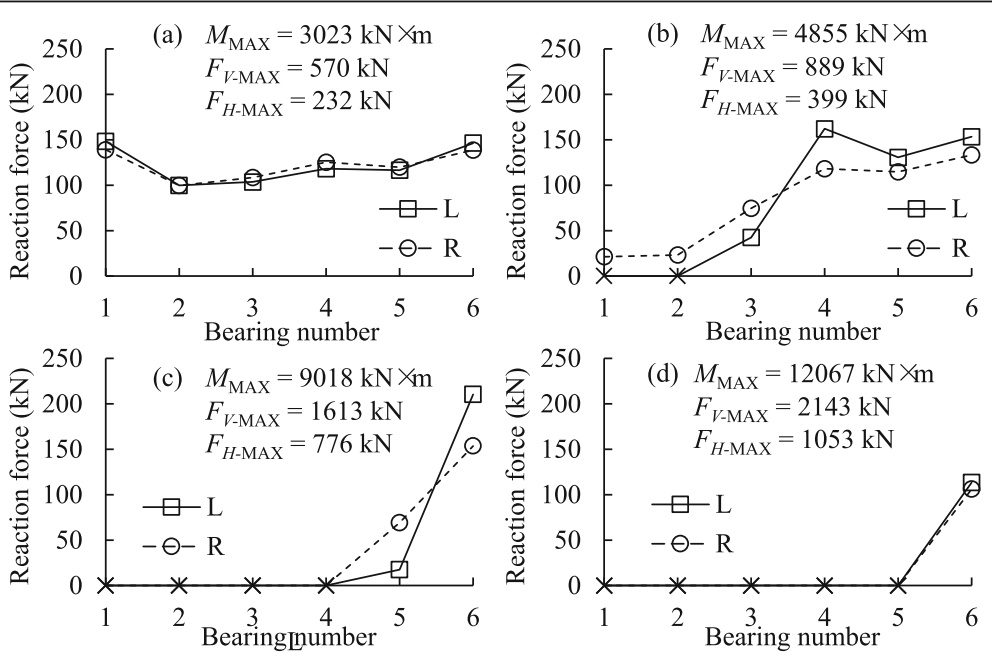

Note: $\square$ and $-\ominus$-for normal working (compressed) states; $\nsucc$ for damaged states.

Fig. 6 Bearing working states under different overturning moments 
bridge deck could be easily overturned by the wave impacts. Identification of such failure mode and calculation corresponding limit states are of vital importance.

By applying different external overturning moment on the bridge model, the bearing reaction forces and limit states can be calculated. After several calculations, once external moment $M$ exceeds $7696 \mathrm{kN} \times \mathrm{m}$, bearings at seaward side will damage including L1 - L3 and R1 - R3. At this moment, the deck loses all the constraints in $x$ direction, and structural stability cannot be guaranteed. Thus, $7696 \mathrm{kN} \times \mathrm{m}$ is determined as the limit state for the overturning effect by considering bearing performance.

\section{Probabilistic vulnerability model for coastal bridge under wave impact}

\subsection{Fragility model and bridge capacity considering overturning moment}

To account for the wave induced forces and overturning moment effects on the bridge deck, the limit state function of the bridge failure model is developed as

$$
P=\left[C_{F} \leq D_{F} \text { or } C_{M} \leq D_{M}\right]
$$

where $C$ = structural capacity; $D=$ structural demand; $P(F)=$ the probability failure of the bridge span; and the subscript $F$ and $M$ represent failure caused by force and moment, respectively. The structural capacity for vertical wave force is mainly provided by deck weight

$$
C_{F}=W_{s}=\left(d_{b} W+A_{g} n_{g}\right) \gamma l
$$

where $W_{s}=$ the static weight of the deck; $d_{b}=$ deck thickness; $W=$ the deck width; $A_{g}=$ cross-sectional area of girders; $n_{g}=$ girder number; $\gamma=$ unit weight of the deck; and $l=$ span length. With respect to the overturning failure mode, the structural capacity $C_{M}=7696$ $\mathrm{kN} \times \mathrm{m}$ is computed from the bridge FE model considering bearing working states.

\subsection{Probabilistic demand model for wave load and overturning moment}

The structural demand parameters associated with bridge failure caused by force and moment $\left(D_{F}\right.$ and $\left.D_{M}\right)$ are the maximum vertical wave force and overturning moment on the bridge deck. Although the 3D CFD numerical model could compute reliable results for different cases, it is limited to its high computational cost, which is not conducive to large-scale calculations, especially for vulnerability and risk analyses. To address this issue, surrogate models are utilized in this study to predict wave induced force and moment. Such mathematical method establishes the correlation between structural demand with hazard intensities (wave parameters) based on numerical results. And the proposed surrogate model could be utilized to compute wave force and moment under various conditions, which highly improves computational efficiency.

Considering different characteristics of wave force and overturning moment under different inundation conditions, different surrogate models are selected for unsubmerged and submerged cases. A total of 108 data sets are used to train the surrogate model, 54 for unsubmerged cases and the other 54 for submerged cases. In this study, the stepwise regression method is used to identify the most critical factors contributing to the wave induced force and overturning moment from water depth $D$, wave height $H$, clearance $Z_{c}$, and coefficients wave period $T$, wavelength $\lambda$, wave steepness $H / \lambda$, which are calculated based on the solitary wave generation theory (Goring 1978), and their interactions with each other (i.e., the product of two indexes). After several 
calculations and comparisons, a second order polynomial regression model is adopted and wave height $H$ and clearance $Z_{c}$ are taken as two model predictors. In addition, a normally distributed model error term $v$, with 0 mean and standard deviation equal to the root-mean-square error (RMSE), is added to consider the lack of fit (Segura et al. 2019). The general equation is as (Simpson et al. 2001)

$$
y^{\prime}=\theta_{0}+\sum_{i=1}^{q} \theta_{i} m_{i}+\sum_{i=1}^{q} \sum_{j=1}^{q} \theta_{i j} m_{i} m_{j}+v
$$

where $m_{i}$ and $m_{j}=$ the model predictors (i.e., $H$ and $Z_{c}$ ); $\theta_{i}$ and $\theta_{i j}=$ fitting coefficients; and $q=$ the number of total predictors taken as 2 . The coefficient of determination $\left(R^{2}\right)$ and the root-mean-square error (RMSE) are adopted as the goodness-of-predict, which are calculated as

$$
\begin{aligned}
& R^{2}=1-\frac{\sum_{i=1}^{q}\left(y_{i}-y_{i}^{\prime}\right)^{2}}{\sum_{i=1}^{q}\left(y_{i}-y_{\text {mean }}\right)^{2}} \\
& \text { RMSE }=\sqrt{\sum_{i=1}^{q} \frac{\left(y_{i}-y_{i}^{\prime}\right)^{2}}{n}}
\end{aligned}
$$

where $y^{\prime}=$ predicted values calculated by the surrogate model; $y=$ simulated values from CFD model; $y_{\text {mean }}=$ the mean value of the samples; and $y_{\max }$ and $y_{\min }=$ the $\max$ imum and minimum sample, respectively.

The fitting coefficients $\theta_{i}$ and $\theta_{i j}$, and performance indexes RMSE and $R^{2}$ are listed in Table 2. Also, comparisons of simulated results from the CFD model and predicted values using the surrogate models are presented in Fig. 7. Generally, good fittings are observed, proving the accuracy of the established surrogate models.

\subsection{Uncertainties associated with structural demand and capacity}

The numerical model computes a deterministic relationship between structural demand and wave parameters, while uncertainties associated with structural capacity and intensity measures should be considered for real bridge conditions. For example, the concrete and steel strength could be slightly different from the standard values, which would affect the overall capacity of the bridge. Thus, a probabilistic vulnerability

\begin{tabular}{|c|c|c|c|c|c|c|c|c|c|}
\hline \multicolumn{2}{|c|}{ Unsubmerged } & RMSE & $R^{2}$ & $\theta_{0}$ & $\theta_{1}$ & $\theta_{2}$ & $\theta_{11}$ & $\theta_{12}$ & $\theta_{22}$ \\
\hline$F_{V-\text { MAX }}$ & \multirow{3}{*}{$\begin{array}{l}m_{1}=H \\
m_{2}=Z_{c}\end{array}$} & 403.6 & 0.909 & -1299 & 1132 & -410.9 & -32.75 & 172.6 & -400.3 \\
\hline$F_{\text {H-MAX }}$ & & 140 & 0.943 & -1899 & 1077 & -569.2 & -77.37 & 112.1 & -10.87 \\
\hline$M_{\text {MAX }}$ & & 1863 & 0.897 & 3593 & 3465 & -8261 & 7.948 & 1446 & -725.2 \\
\hline \multicolumn{2}{|c|}{ Submerged } & RMSE & $R^{2}$ & $\theta_{0}$ & $\theta_{1}$ & $\theta_{2}$ & $\theta_{11}$ & $\theta_{12}$ & $\theta_{22}$ \\
\hline$F_{V-\operatorname{MAX}}$ & \multirow{3}{*}{$\begin{array}{l}m_{1}=H \\
m_{2}=Z_{c}\end{array}$} & 401.2 & 0.828 & 2042 & 481.8 & 1781 & -6.311 & 29.63 & 349.7 \\
\hline$F_{H-\text { MAX }}$ & & 117.7 & 0.901 & 139.7 & 56.96 & -183.9 & 33.69 & 39.82 & -35.89 \\
\hline$M_{\text {MAX }}$ & & 1059 & 0.879 & 7950 & 2771 & 5087 & 57.73 & 831 & 842.9 \\
\hline
\end{tabular}
analysis, rather than a deterministic one, is utilized and introduced herein.

Table 2 Fitting and performance coefficients for different inundation scenarios 

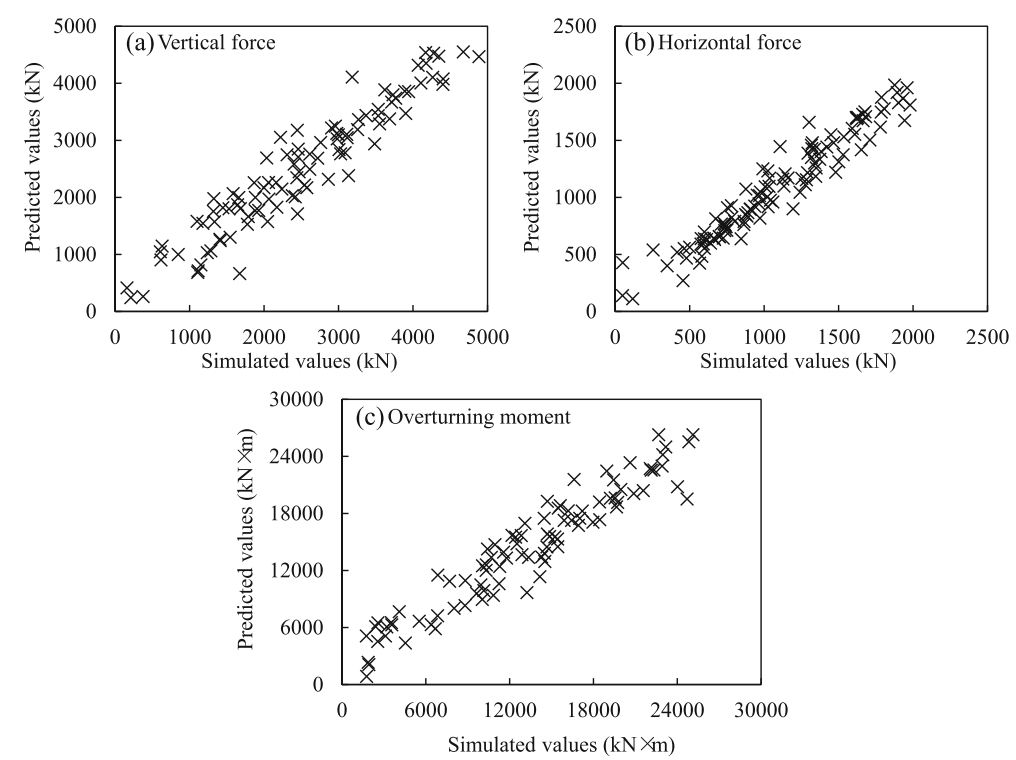

Fig. 7 Comparisons of the CFD simulated results and surrogate model predicted values

Wave height influences wave force and overturning moment significantly. Since most coastal bridges are located near the coastline, a Weibull-generalized Pareto (WGP) model (Wu et al. 2016), that was proposed based on long-term field observation record in shallow water depth, is employed to model the wave height distribution as

$$
\begin{array}{ll}
f_{W}(h)=\frac{\kappa \phi}{\rho H_{s}}\left(\frac{h}{\rho H_{s}}\right)^{\kappa-1} \exp \left[-\phi\left(\frac{h}{\rho H_{s}}\right)^{\kappa}\right] & h \leq H_{s} \\
\kappa=2\left(1-\omega\left(\frac{H_{s}}{D}\right)^{1.7}\right)^{-1} & \\
f_{G P}(h)=\frac{1}{\alpha \rho H_{s}}\left(1+\frac{\xi}{\alpha} \frac{\left(h-\rho H_{s}\right)}{\rho H_{s}}\right)^{-\frac{1}{\xi}-1} & h>H_{s} \\
\xi=\alpha\left(1-2 \beta \pi \frac{\tanh \left(k_{L} D\right)}{k_{L} \rho H_{s}}\right)^{-1} &
\end{array}
$$

where $f_{W}(h)=$ the Weibull distribution function; $f_{G P}(h)=$ the Generalized Pareto distribution function; $h=$ wave height; $H_{s}=$ significant wave height; $\phi=$ Weibull distribution scale parameter taken as $5 ; \omega=$ adjustment coefficient taken as $1 ; k_{L}=$ wave number; $\alpha$ $=$ GP scale parameter taken as $0.22 ; \beta=$ Miche limit coefficient taken as 0.15 (Miche 1944); and $\rho=$ estimation factor taken as 1 (Wu et al. 2016). The significant wave height $H_{s}$ during a hurricane event can be calculated as (CERC 1984)

$$
\begin{aligned}
& H_{s}=5.112 \times 10^{-4} U_{A} F^{1 / 2} \\
& U_{A}=0.71 U_{\max }^{1.23}
\end{aligned}
$$

where $U_{A}=$ the wind stress factor; $F=$ the fetch length, which is treated deterministically as $5000 \mathrm{~m}$; and $U_{\max }=$ the maximum hurricane wind speed. The maximum hurricane wind speed $U_{\max }$, is determined as a function of the return period (RT) for hurricanes 
based on the field weather record data (Malmstadt et al. 2010). The maximum wind speeds corresponding to a RT of 10, 20, 50, 100, and 500 years are $47 \mathrm{~m} / \mathrm{s}, 56 \mathrm{~m} / \mathrm{s}, 62 \mathrm{~m} / \mathrm{s}$, $65 \mathrm{~m} / \mathrm{s}$, and $68 \mathrm{~m} / \mathrm{s}$, respectively (Malmstadt et al. 2010).

The storm induced surge height is also stochastic and affected by the complex meteorological environment. A uniform distribution ranging $\pm 20 \%$ is utilized for the surge height (Saeidpour et al. 2019). And the mean value of surge height is taken as a linear function with $U_{\max }$ (Liang and Julius 2011).

With respect to the structural capacity, uncertainties in density of construction materials and structural dimensions are considered. According to JCSS (2001), the reinforced concrete density follows a normal distribution with a mean of $2400 \mathrm{~kg} / \mathrm{m}^{3}$ and a coefficient of variation (COV) of 0.04 . For steel, the mean density is $7850 \mathrm{~kg} / \mathrm{m}^{3}$ and COV is 0.01 . A uniform distribution from $95 \%$ to $105 \%$ is used for deck thickness. The calculated bridge deck density thus follows a normal distribution with a mean value of $2.2 \times 10^{5} \mathrm{~kg} / \mathrm{m}^{3}$ and a COV of 0.036 . Similarly, the overturning capacity also is considered as normally distributed with a COV of 0.036 .

\section{Fragility and long-term loss analysis for coastal bridge under hurricane hazard}

\subsection{Fragility curves under different hurricane scenarios}

Based on the probabilistic fragility model introduced above, fragility curves can be derived for the coastal bridge under different hurricane hazard scenarios as shown in Fig. 8. Generally, the failure probability increases with the hurricane wind speed, and the bridge is less likely to be affected by storm surge and waves with small wind speeds (smaller than $35 \mathrm{~m} / \mathrm{s}$ ). The failure model without considering the overturning effect has a smaller failure probability, which means it may underestimate the risk of hurricane to the bridge. The bridge failure probability under different hurricane scenarios can be identified from Fig. 8 and could be utilized for the long-term loss analysis.

\subsection{Long-term loss quantification for hurricane hazards}

The loss severity is calculated as the product of the repair cost of the bridge and the conditional probability of the bridge being in a specified damage state under a given intensity measure (Giouvanidis and Dong 2020). In this study, the cost of bridge

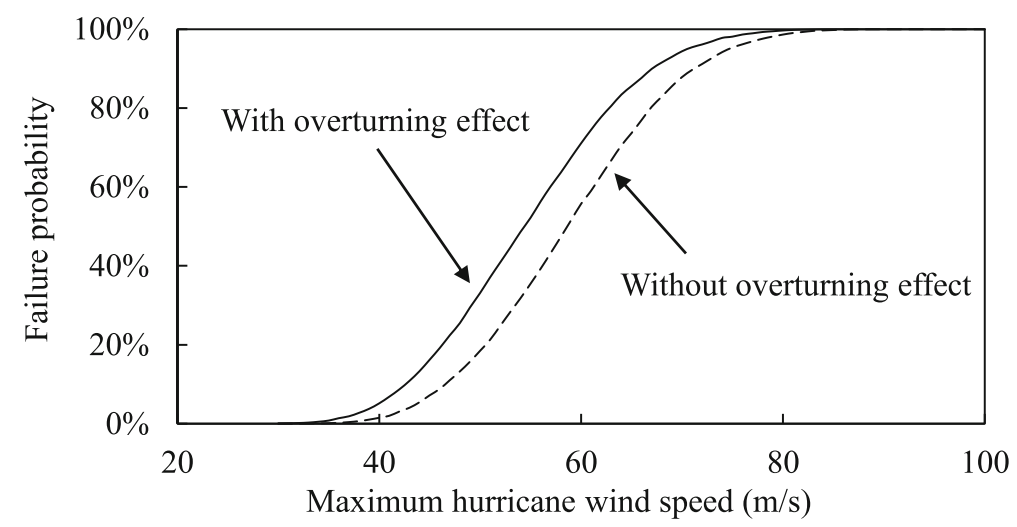

Fig. 8 Fragility curves for coastal bridge under different hurricane scenarios with and without considering overturning effect 
superstructure replacement is taken as 1.283 million US dollars (USD) based on previous investigations (Mondoro et al. 2017). The future loss is discounted to the present value using a monetary discount rate $r$. Thus, the proposed long-term loss can be determined by summing the losses from individual hurricane hazards during the investigated time period as

$$
\begin{aligned}
& \operatorname{LTL}\left(t_{\mathrm{int}}\right)=\sum_{i=1}^{N\left(t_{\text {int }}\right)} L_{i} e^{-r T_{i}} \\
& L_{i}=P_{i} L_{r}
\end{aligned}
$$

where $L T L=$ total loss for the $i$ th hazard; $L_{i}=$ financial loss due to structural failure under the $i$ th hazard event; $T_{i}=$ arrival time of the $i$ th hazard; $P_{i}=$ bridge failure probability under the $i$ th hurricane; $L_{r}=$ deck replacement cost; and $r=$ financial discount rate used to convert future loss to present taken as $2 \%$.

The long-term loss LTL $\left(t_{\text {int }}\right)$ is related to the stochastic models. A homogeneous Poisson process $\left\{N\left(t_{\text {int }}\right), t_{\text {int }}>0\right\}$ is implemented for loss assessment, the inter-arriving time $W_{i}$ follows an exponential distribution, and the number of arrivals $N\left(t_{\text {int }}\right)$ has a Poisson distribution (Li et al. 2020ab). Then, the expected number of hazard arrivals can be expressed as $E\left[N\left(t_{\text {int }}\right)\right]=\lambda t_{\text {int }}$ with $N(0)=0$. The expected long-term loss can be derived as (Li et al. 2020b)

$$
E\left[L T L\left(t_{\text {int }}\right)\right]=\frac{E[L] \lambda}{r}\left(1-e^{-r t_{\text {int }}}\right)
$$

Figure 9 shows the expected long-term damage loss changing over the investigated time period under different hurricane scenarios, and the results calculated with and without considering overturning failure mechanisms are plotted. It is identified from the long-term loss that a hurricane hazard with a 20-year RT will lead to the highest expected long-term loss throughout the investigated period. This feature is mainly due to its relatively high occurrence frequency compared with other intensity levels, although the single damage loss is small. On the contrary, the 500-year RT hurricane scenario would cause the lowest long-term loss of the bridge for its low occurrence frequency. It can be observed by comparing Figs. 9a and b that neglecting the

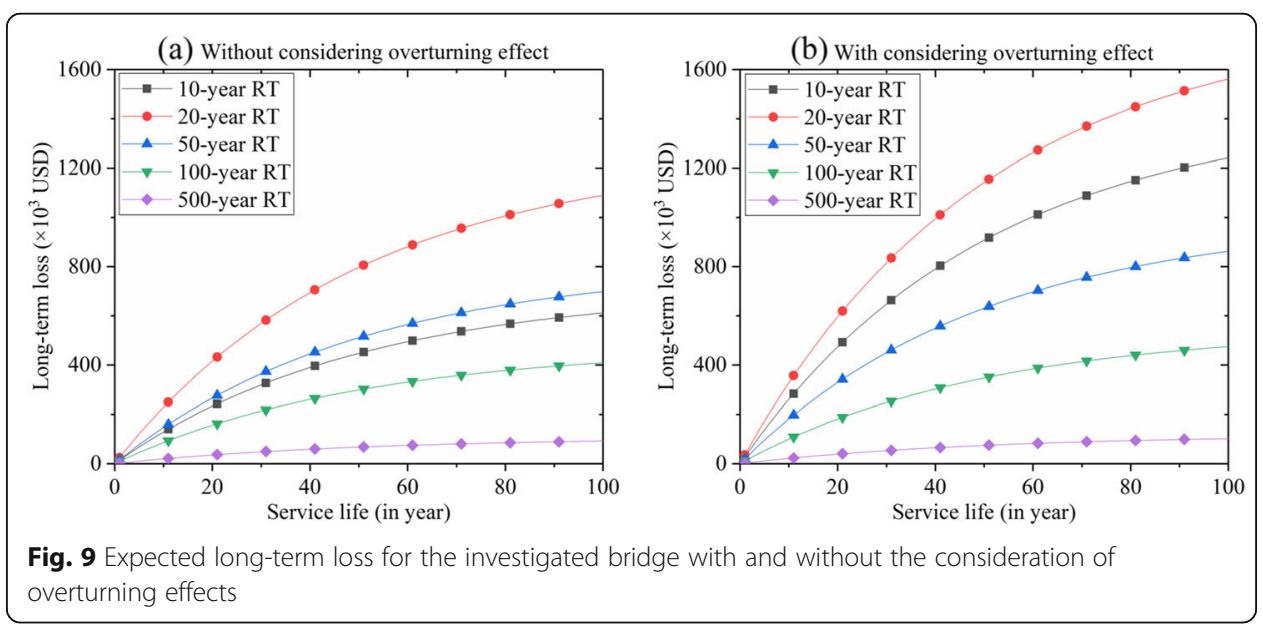


overturning effect would underestimate the long-term damage loss by $20-30 \%$. Based on the expected long-term loss for the investigated bridge, decision-makers could further formulate countermeasures against hurricanes.

\section{Conclusions}

This study provides an elaborate framework to assess the vulnerability and long-term loss of coastal bridge subjected to hurricane hazards based on 3D numerical analyses. A 3D CFD numerical model is established to investigate wave-bridge interaction and a FE model is established for the bridge to further calculate structural responses under wave impacts. Based on the numerical results, a probabilistic vulnerability model is developed considering the effects of wave force and overturning moment. Structural demand, capacity, and limit states are determined for the investigated failure modes. Uncertainties arising from wave parameters, structural capacity, and material properties and the resulting consequences are considered. Then, fragility curves are calculated, and long-term damage loss is assessed.

The CFD simulation of the wave-deck interaction calculates the wave-induced force and overturning moment on the bridge deck. Combined with structural responses analyses, it reveals that the extreme overturning moment could lead to bearing constraint damage before the deck is lifted by the waves. Such phenomenon indicates the necessity of considering overturning failure mechanism when analyzing structural performance under the hurricane wave impact.

Accordingly, a bridge fragility model considering the effects of wave force, overturning moment, and bearing constraints is developed. Fragility analysis and long-term loss assessment with and without considering overturning effects are performed. The results show that neglecting the overturning effects could not fully assess bridge failure probability under different hurricane scenarios, and it would underestimate the long-term loss by $20-30 \%$. Therefore, the overturning effects should be considered when formulating countermeasures for coastal bridges against hurricanes.

The proposed approach can benefit the management and design of coastal bridges against the impacts of hurricane hazards. Further studies are expected to consider other types of highway bridges and climate change effects.

\footnotetext{
Abbreviations

AASHTO: American Association of State Highway and Transportation Officials; ACl: American Concrete Institute; CERC: The Coastal Engineering Research Center; CFD: Computational Fluid Dynamics; COV: Coefficient of Variation; FE: Finite Element; JCSS: Joint Committee on Structural Safety; LTL: Long-term Loss; RMSE: Root Mean Square Error; RT: Return Period; UDF: User Defined Functions; USD: US dollars; VOF: Volume of Fluid; WGP: Weibull-generalized Pareto
}

Acknowledgements

The authors gratefully acknowledge Mr. Jing Qian and Mr. Hongyuan Guo for the support in terms of surrogate model calculation.

Authors' contributions

Deming Zhu: Conceptualization, Methodology, CFD modeling, Writing - original draft. Yaohan Li: Loss assessment, Writing - review\& editing. You Dong: Visualization, Investigation, Writing - review\& editing, Supervision. Peng Yuan: FE modeling. The authors read and approved the final manuscript. 
Availability of data and materials

No other data sources need to be provided and no data will be shared.

\section{Competing interests}

The authors declare that they have no known competing financial interests or personal relationships that could have appeared to influence the work reported in this paper.

\section{Author details}

${ }^{1}$ Shenzhen Urban Transport Planning Center Co., Ltd, Shenzhen, China. ${ }^{2}$ Department of Civil and Environmental Engineering, The Hong Kong Polytechnic University, Hung Hom, Kowloon, Hong Kong.

Received: 6 December 2020 Accepted: 25 December 2020

Published online: 08 April 2021

\section{References}

AASHTO. (2008). Guide specifications for bridges vulnerable to coastal storms

American Concrete Institute (ACI) (2014). Building Code Requirements for Structural Concrete and Commentary (ACI 318-14), American Concrete Institute, Farmington Hills, MI, USA.

Ataei N, Padgett JE (2013) Probabilistic modeling of bridge deck unseating during hurricane events. J Bridg Eng 18(4):275286

Ataei N, Padgett JE (2015) Influential fluid-structure interaction modelling parameters on the response of bridges vulnerable to coastal storms. Struct Infrastruct Eng 11(3):321-333

Cai Y, Agrawal A, Qu K, Tang HS (2018) Numerical investigation of connection forces of a coastal bridge deck impacted by solitary waves. J Bridg Eng 23(1):04017108

Caltrans. (1994). Bridge memo to designers. Section 7: Bridge Bearings

Coastal Engineering Research Center (CERC) (1984). Shore Protection Manual in Department of the Army, Waterways Experiment Station, Corps of Engineers. Vicksburg, MS: The U.S. Army Engineer Waterways Experiment Station Coastal Engineering Research Center.

Chen X, Chen Q, Zhan J, Liu D (2016b) Numerical simulations of wave propagation over a vegetated platform. Coast Eng 110:64-75

Chen X, Chen Z, Cai S, Xu W, Zhuo X, Lv J, \& Zhao J. (2020). Numerical investigation of dynamic responses and mooring forces of submerged floating tunnel driven by surface waves. Sci Rep, 10(1):1-19.

Chen X-b, Zhan J, Chen Q, Cox D (2016a) Numerical modeling of wave forces on movable bridge decks. J Bridg Eng 21(9): 04016055

Dong Y, Akiyama M, Frangopol DM, \& Tsompanakis Y. (2020). Risk-, resilience-, and sustainability-informed assessment and management of civil infrastructure in a life-cycle context. Structure and Infrastructure Engineering, 2020:1-2.

Dong Y, Frangopol DM (2017) Probabilistic assessment of an interdependent healthcare-bridge network system under seismic hazard. Struct Infrastruct Eng 13(1):160-170

Douglass SL, Hughes S, Rogers S, \& Chen Q. (2004). The impact of Hurricane Ivan on the coastal roads of Florida and Alabama: A preliminary report. Rep. to Coastal Transportation Engineering Research and Education Center, Univ. of South Alabama, Mobile, Ala.

Frangopol DM, Dong Y, Sabatino S (2017) Bridge life-cycle performance and cost: analysis, prediction, optimisation and decision-making. Struct Infrastruct Eng 13(10):1239-1257

Giouvanidis Al, Dong Y (2020) Seismic loss and resilience assessment of single-column rocking bridges. Bull Earthq Eng 18(9): $4481-4513$

Goring DG. (1978). Tsunamis--the propagation of long waves onto a shelf.

Guo A, Fang Q, Bai X, \& Li H. (2015). Hydrodynamic experiment of the wave force acting on the superstructures of coastal bridges. Journal of Bridge Engineering, 20(12);04015012:1-11.

Hayatdavoodi M, Seiffert B, Ertekin RC (2014) Experiments and computations of solitary-wave forces on a coastal-bridge deck. Part II: deck with girders. Coast Eng 88:210-228

Joint Committee on Structural Safety (JCSS). (2001). JCSS probabilistic model code. 3: Resistance models. Joint Committee on Structural Safety 2010:12-90. http://www.jcss.ethz.ch/publications.

Kameshwar S, Padgett JE (2014) Multi-hazard risk assessment of highway bridges subjected to earthquake and hurricane hazards. Eng Struct 78:154-166

Khaleghi, B., Warren, L., Fu, Z., Zeldenrust, R., Kestory, E., Stanton, J. F., Mongi, A. N., Walsh, J., Nix, R., et al. (2019). Experiences in the Performance of Bridge Bearings and Expansion Joints Used for Highway Bridges

Li Y, Dong Y, Frangopol DM, Gautam D (2020a) Long-term resilience and loss assessment of highway bridges under multiple natural hazards. Struct Infrastruct Eng 16(4):626-641

Li Y, Dong Y, \& Qian J. (2020b). Higher-order analysis of probabilistic long-term loss under nonstationary hazards. Reliability Engineering \& System Safety, 203;107092:1-12

Li Y, Dong Y, Zhu D (2020c) Copula-based vulnerability analysis of civil infrastructure subjected to hurricanes. Front Built Environ 6:170

Liang MS, Julius S (2011) On the coastal topography and storm surge for infrastructure risk assessment and adaptation. World Environ Water Resour Congress 2017:232-240

Malmstadt JC, Elsner JB, Jagger TH (2010) Risk of strong hurricane winds to Florida cities. J Appl Meteorol Climatol 49(10): $2121-2132$

Miche, M. Mouvements ondulatoires de la mer en profondeur constante ou décroissante. Annales de Ponts et Chaussées, 1944:26-406.

Mondoro A, Frangopol DM, \& Soliman M. (2017). Optimal risk-based management of coastal bridges vulnerable to hurricanes. Journal of Infrastructure Systems, 23(3);04016046:1-15. 
Padgett J, Desroches R, Nielson B, Yashinsky M, Kwon OS, Burdette N, Tavera E (2008) Bridge damage and repair costs from hurricane Katrina. J Bridg Eng 13(1):6-14

Robertson IN, Riggs RH, Yim SCS, Young YL (2007) Lessons from hurricane Katrina storm surge on bridges and buildings. J Waterw Port Coast Ocean Eng 133(6):463-483

Robertsson JOA, Blanch JO (2020) Numerical Methods, Finite Difference, pp 1-9

Saeidpour A, Chorzepa MG, Christian J, Durham S (2019) Probabilistic hurricane risk analysis of coastal bridges incorporating extreme wave statistics. Eng Struct 182(June 2018):379-390

Sarpkaya T, Isaacson M (1981) Mechanics of wave forces on offshore structures

Segura RL, Padgett JE, Paultre P (2019) Polynomial response surface-based seismic fragility assessment of concrete gravity dams. In: 12th Canadian Conference on Earthquake Engineering, June, pp 1-8

Seiffert B, Hayatdavoodi M, Ertekin RC (2014) Experiments and computations of solitary-wave forces on a coastal-bridge deck. Part I: flat plate. Coast Eng 88:194-209

Simpson TW, Peplinski JD, Koch PN, Allen JK (2001) Metamodels for computer-based engineering design: survey and recommendations. Eng Comput 17(2):129-150

Wu Y, Randell D, Christou M, Ewans K, Jonathan P (2016) On the distribution of wave height in shallow water. Coast Eng 111: $39-49$

Xu G (2020) Discussion of "numerical investigation of connection forces of a coastal bridge deck impacted by solitary waves" by Yalong Cai, A. Agrawal, Ke Qu, and H. S. Tang. J Bridge Eng 25(1):1-2

X G G, Cai CS (2015a) Numerical simulations of lateral restraining stiffness effect on bridge deck--wave interaction under solitary waves. Eng Struct 101:337-351

Xu G, Cai CS (2015b) Wave forces on Biloxi Bay bridge decks with inclinations under solitary waves. J Perform Constr Facil 29(6):4014150

Xu G, Cai CS, Han Y (2016) Investigating the characteristics of the solitary wave-induced forces on coastal twin bridge decks. J Perform Constr Facil 30(4):4015076

Zhu D, Dong Y (2020) Experimental and 3D numerical investigation of solitary wave forces on coastal bridges. Ocean Eng 209:107499

\section{Publisher's Note}

Springer Nature remains neutral with regard to jurisdictional claims in published maps and institutional affiliations.

\section{Submit your manuscript to a SpringerOpen ${ }^{\circ}$ journal and benefit from:}

- Convenient online submission

Rigorous peer review

- Open access: articles freely available online

High visibility within the field

- Retaining the copyright to your article

Submit your next manuscript at $\boldsymbol{\nabla}$ springeropen.com 